\title{
Command and Compensation in a Neuromodulatory Decision Network
}

\author{
Haojiang Luan, Fengqiu Diao, Nathan C. Peabody, and Benjamin H. White \\ Laboratory of Molecular Biology, National Institute of Mental Health, NIH, Bethesda, Maryland 20892
}

The neural circuits that mediate behavioral choices must not only weigh internal demands and environmental circumstances, but also select and implement specific actions, including associated visceral or neuroendocrine functions. Coordinating these multiple processes suggests considerable complexity. As a consequence, even circuits that support simple behavioral decisions remain poorly understood. Here we show that the environmentally sensitive wing expansion decision of adult fruit flies is coordinated by a single pair of neuromodulatory neurons with command-like function. Targeted suppression of these neurons using the Split Gal4 system abrogates the fly's ability to expand its wings in the face of environmental challenges, while stimulating them forces expansion by coordinately activating both motor and neuroendocrine outputs. The arbitration and implementation of the wing expansion decision by this neuronal pair may illustrate a general strategy by which neuromodulatory neurons orchestrate behavior. Interestingly, the decision network exhibits a plasticity that is unmasked under conducive environmental conditions in flies lacking the function of the command-like neuromodulatory neurons. Such flies can often expand their wings using a motor program distinct from that of wild-type animals and controls. This compensatory program may be the vestige of an ancestral, environmentally insensitive program used for wing expansion that existed before the evolution of the environmentally adaptive program currently used by Drosophila and other cyclorrhaphan flies.

\section{Introduction}

How and where in the nervous system behavioral decisions are made is unknown with any degree of precision for most behaviors. Studies in primates reveal a critical role for forebrain structures in decisions that require memory and motor planning (Gold and Shadlen, 2007; Kable and Glimcher, 2009), but decerebrate animals without these structures make basic behavioral decisions regarding survival and reproduction, indicating that there are additional decision-making loci, probably involving the hypothalamus and brainstem (Swanson, 2000; Humphries et al., 2007). Decisions that require these structures are often accompanied by changes in neuroendocrine or visceral function that support the behaviors being executed, but very little is known about the mechanisms coordinating either the motor patterns that constitute behavioral programs or the concomitant autonomic changes.

More is known about the implementation of behavioral decisions in invertebrates, where motor pattern generators have been

\footnotetext{
Received July 20, 2011; revised Nov. 7, 2011; accepted Nov. 28, 2011.

Author contributions: H.L., F.D., N.C.P., and B.H.W. designed research; H.L., F.D., N.C.P., and B.H.W. performed research; H.L., F.D., and B.H.W. analyzed data; H.L., N.C.P., and B.H.W. wrote the paper.

This work was supported by the Intramural Research Program of the National Institute of Mental Health (Project 1ZIA-MH-002800-07). We thank Kevin HoWan, Sarrah Ben-Achour, and Michael Syme for technical assistance in generating and characterizing the enhancer-trap hemidriver lines. We thank Aaron Hsueh and Willi Honnegger for the anti-pburs antibody, Deborah Hursh for UAS-hid flies, and Grace Gray for critical comments on the manuscript. We would also like to express our profound gratitude to the late Howard Nash whose encouragement, generous advice, and thoughtful comments were invaluable throughout.

The authors declare no competing financial interest.

Correspondence should be addressed to Benjamin H. White, National Institute of Mental Health, NIH, 9000 Rockville Pike, Bethesda, MD 20892. E-mail: benjaminwhite@mail.nih.gov.

H. Luan's present address: Janelia Farm Research Campus, Howard Hughes Medical Institute, 19700 Helix Drive, Ashburn, VA 20147

DOI:10.1523/JNEUROSCI.3707-11.2012

Copyright $\odot 2012$ the authors $\quad 0270-6474 / 12 / 320880-10 \$ 15.00 / 0$
}

characterized with cellular and molecular resolution (Marder and Bucher, 2001; Kristan et al., 2005; Katz and Hooper, 2007). In keeping with the overall similarity of motor control in vertebrates and invertebrates (Kien and Altman, 1992; Büschges et al., 2011; Mullins et al., 2011), these pattern generators have been shown in numerous cases to be regulated by more rostrally disposed higher-order neurons (Kupfermann and Weiss, 2001) capable of initiating behavioral components of escape (Edwards et al., 1999), locomotion (Friesen and Kristan, 2007), feeding (Kupfermann and Weiss, 2001; Elliott and Susswein, 2002), mating (Hedwig, 2006; von Philipsborn et al., 2011), and postural change (Larimer and Moore, 2003; Mesce et al., 2008). As in vertebrates, however, it is generally not understood how component motor patterns are integrated to produce coherent whole-animal behavior.

Neuromodulators, with their diverse targets and capacity to reconfigure pattern-generating networks, are attractive candidates for accomplishing behavioral integration (Nusbaum et al., 2001; Dickinson, 2006) and are known to elicit basic behaviors when introduced into the CNS (Kow et al., 1994; Leibowitz and Wortley, 2004). Recent work using genetic techniques to target specific cell populations confirms that neuromodulatory neurons can coordinate complex motor output. For example, by selectively activating hypothalamic neurons that express agoutirelated peptide, a known, positive modulator of feeding, Aponte et al. (2011) demonstrated the robust induction of eating behavior in mice. Likewise, stimulation of neurons in Drosophila that express the neuropeptide CCAP (i.e., crustacean cardioactive peptide) and other factors (Kim et al., 2006) induces the motor program underlying wing expansion in newly emerged adults (Peabody et al., 2009). Interestingly, the latter manipulation 
concomitantly triggers hormonal release to facilitate somatic changes that support expansion (Reynolds, 1977; Luan et al., 2006b), making this system a useful model for studying the coordination of behavioral and neuroendocrine output in behavioral decisions.

Here we dissect the architecture of command in the CCAP network. We find that a single pair of neuromodulatory neurons located in the subesophageal ganglion coordinates the activation of the wing expansion motor program and the neuroendocrine output neurons in inhibitory environments. Surprisingly, in noninhibitory environments, the suppression of behavioral command can be compensated for by other motor patterns.

\section{Materials and Methods}

Fly culture/crosses. All flies were grown on cornmeal-molasses medium and maintained at $25^{\circ} \mathrm{C}$ in a constant $12 \mathrm{~h} \mathrm{light-dark} \mathrm{cycle.} \mathrm{The} \mathrm{following}$ lines used in this study have been described previously: w;CCAP-Gal4;+ (Park et al., 2003), w; UAS-TRPM8 ${ }^{\text {C4D }}$; + ; ; +; UAS-TRPM8 ${ }^{\text {C4A }}$ (Peabody et al., 2009), w; Burs-Gal4;+ (Peabody et al., 2008), yw;+;UASKir2.1 (Paradis et al., 2001); w; +;UAS-EGFP (Halfon et al., 2002). We thank Deborah Hursh (FDA, Bethesda, MD) for the UAS-hid line. The UAS-pburs-RNAi line (\#27141) and the UAS-dicer-2 line (\#60014) used to facilitate RNAi-mediated knockdown in the $\mathrm{B}_{\mathrm{AG}}$ neurons were from the Vienna Drosophila RNAi Center (Dietzl et al., 2007).

Generation of the $B_{S E G}$ and $B_{A G}$ Split-Gal4 hemidrivers. The Burs ${ }^{\text {Gal4DBD }}$ construct, which is designed to express the Gal4 DNAbinding domain under the control of the bursicon $\alpha$-subunit (i.e. burs) promoter, was made from the previously described elav Gal4DBD construct (Luan et al., 2006a). The elav promoter was first removed by EcoRI and NotI digestion and replaced with the $252 \mathrm{bp}$ burs promoter described previously (Peabody et al., 2008). Transgenic lines were made by Rainbow Transgenic Flies and a third chromosome insert (i.e., Burs ${ }^{\text {Gal4DBD }}$ U6A1) was used.

VP16AD enhancer trap lines were generated by p-element mobilization in previously published lines (Luan et al., 2006a) using the transposase-bearing line, $w ;+; \Delta 2-3$ (a gift from Dr. Yuzhong Cheng; NICHD, Bethesda, MD) and standard methods (Grigliatti, 1998). Approximately $400 \mathrm{ET}^{\mathrm{VP} 16 \mathrm{AD}}$ lines were made and subsequently screened for expression within the bursicon-expressing neurons by crosses to a line carrying both the Burs ${ }^{\text {Gal4DBD }}$ and UAS-EGFP transgenes. The $\mathrm{ET}^{\mathrm{VP16AD}}$-99 line, with principal expression in the two bursiconexpressing neurons of the subesophageal ganglion $\left(\mathrm{B}_{\mathrm{SEG}}\right)$ and the $\mathrm{ET}^{\mathrm{VP} 16 \mathrm{AD}}$-N9A88A line, with expression in the 14 bursicon-expressing neurons of the abdominal ganglion $\left(\mathrm{B}_{\mathrm{AG}}\right)$ were used in this study. Both lines carry second chromosome inserts of the transgene. Consensus patterns of UAS-EGFP expression for these hemidrivers paired with Burs Gal4DBD were determined as described by Luan et al. (2006b). While strong and exclusive expression in all $14 \mathrm{~B}_{\mathrm{AG}}$ neurons was consistently observed with the ET ${ }^{\mathrm{VP16AD}}$-N9A88A $\cap$ Burs ${ }^{\text {Gal4DBD }}$ combination, developmental expression profiles indicated that the $\mathrm{ET}^{\mathrm{VP16AD}}-99 \cap$ Burs ${ }^{\text {Gal4DBD }}$ combination drove UAS-EGFP expression in at least a subset of $\mathrm{B}_{\mathrm{AG}}$ neurons during metamorphosis in addition to the $\mathrm{B}_{\mathrm{SEG}}$. In approximately two-thirds of newly eclosed adults, there was persistent EGFP expression in one $\mathrm{B}_{\mathrm{AG}}$ neuron, and weaker labeling was sometimes detectable in up to two other $\mathrm{B}_{\mathrm{AG}}$ neurons in one-third of animals. Lowfrequency (i.e., in less than one-third of animals), low-level expression of EGFP was also seen in a nonbursicon-expressing neuron located posteriorly in the abdominal ganglion. However, exclusive expression within the $\mathrm{B}_{\mathrm{SEG}}$ was observed when driving UAS-TRPM8, due either to lower sensitivity of anti-TRPM8 immunostaining relative to EGFP fluorescence or to reduced perdurance of the TRPM8 protein versus EGFP.

Behavioral observations and analysis. Behavioral observations of unperturbed flies were made on single animals transferred as pupae into two types of noninhibitory environment, either a food vial filled with 5 $\mathrm{ml}$ of cornmeal-molasses medium, or a $1 \times 1 \times 3 \mathrm{~cm}$ plastic spectrophotometer cuvette filled with $250 \mu \mathrm{l}$ of $1 \%$ agarose. Pupae were transferred $\sim 18 \mathrm{~h}$ before eclosion and posteclosion behavior was scored either directly by eye for animals in food vials, or by videorecording and later analysis for animals in cuvettes. Videorecording was conducted until the completion of wing expansion, or, in the absence of expansion, for up to $7 \mathrm{~h}$. Walking, grooming, and abdominal flexion bouts were scored. The time to wing expansion and/or flexion was calculated as the time from eclosion until flexion was completed and the abdomen assumed its normal posture, or until the splayed wings had returned to their unsplayed condition. This condition coincided well with the end of abdominal flexion and was easier to score. Mild perturbation was accomplished by gently tapping single animals from the food vial in which they had just eclosed into a fresh food vial and observing them by eye without further perturbation. The inhibitory environment has been described before (Peabody et al., 2009) and consisted of a $0.3 \mathrm{~cm}$ diameter $\times 0.7 \mathrm{~cm}$ length cylindrical glass minichamber. A single animal was placed into a minichamber within $3 \mathrm{~min}$ of eclosion for videorecording and subsequent analysis. For neuronal activation experiments, the chambers were set at $18^{\circ} \mathrm{C}$ for $15 \mathrm{~min}$ to activate the TRPM8 channel and then transferred to a Peltier plate maintained at $25^{\circ} \mathrm{C}$ for videorecording. Videorecording was accomplished with a Sony HDR-FX7 digital video camera. Even wildtype flies in the minichamber sometimes failed to expand their wings after delayed execution of expansional behaviors, likely due to progressive stiffening of the cuticle due to secondary tanning processes (Cottrell, 1962). For convenience, the time to complete flexion and the time to complete wing expansion (which are equivalent in most flies) are collectively labeled in figures as the time of expansional delay.

Air swallowing was analyzed as described previously (Peabody et al., 2008) by measuring the volume of air present in the gut after the termination of wing expansion and/or abdominal flexion. Whereas all other behavioral observations were made on either males or females without discrimination, air swallowing measurements were performed independently on males and females because of the systematic differences in the volumes of swallowed air between the two sexes. Final wing phenotypes were typically scored at least $24 \mathrm{~h}$ after eclosion using previously described criteria (Luan et al., 2006b). For the various manipulations described, statistical differences between experimental and control groups of flies were assessed by two-tailed $t$ test.

Immunohistochemistry and immunoblotting. Whole mounts of the CNS from either males or females were prepared, stained, and analyzed by confocal microscopy as described previously (Luan et al., 2006b) using the following primary antibodies: rabbit anti-burs (anti-bursicon $\alpha$-subunit; 1:5000), rat anti-pburs (anti-bursicon $\beta$-subunit; 1:500; kind gift from Aaron Hsueh; Stanford University, Stanford, CA), and goat antiTRPM8 (1:2000; Everest Biotech). In all cases, donkey serum was used in the blocking solution. Kir2.1 expression was analyzed by EGFP fluorescence, taking advantage of the $N$-terminal EGFP tag on the UAS-Kir2.1 construct (Baines et al., 2001).

To analyze anti-burs immunoreactivity in the $\mathrm{B}_{\mathrm{AG}}$ fibers of the abdominal nerves and the $\mathrm{B}_{\mathrm{SEG}}$ fibers of thoracic segment, $\mathrm{T} 2$, whole-animal fillets were prepared and analyzed as reported previously (Peabody et al., 2008). For box-and-whisker plots of immunohistochemistry and behavioral data, the boxes represent the interquartile range of the data separated by the median value, and the whiskers (error bars) indicate the 10th and 90th percentiles of the data. Outliers are represented as x's.

Hemolymph collection and Western blotting were performed essentially as described by Peabody et al. (2009). Experimental flies of mixed sex were collected within $5 \mathrm{~min}$ of eclosion at room temperature $\left(\sim 24^{\circ} \mathrm{C}\right)$ and put into the inhibitory environment. Within $10 \mathrm{~min}$, they were subjected to a $15 \mathrm{~min}$ temperature shift to $18^{\circ} \mathrm{C}$ and then returned to room temperature for $15 \mathrm{~min}$ before hemolymph collection. Negative control flies were handled in parallel, but without temperature shift (i.e., they spent $30 \mathrm{~min}$ at room temperature) and hemolymph for positive control samples was collected from unperturbed flies within an hour of eclosion. In all cases, samples were pooled from 14-17 flies to collect $1 \mu \mathrm{l}$ of hemolymph. For $3 \mu \mathrm{l}$ of hemolymph, 45-50 flies were needed. Anti-burs antibody was used at 1:2000.

\section{Results}

Neuromodulatory command of wing expansion in adverse environments

Upon emergence from the pupal case, adult fruit flies will perch if the environment is suitable and expand their wings. This process 
A

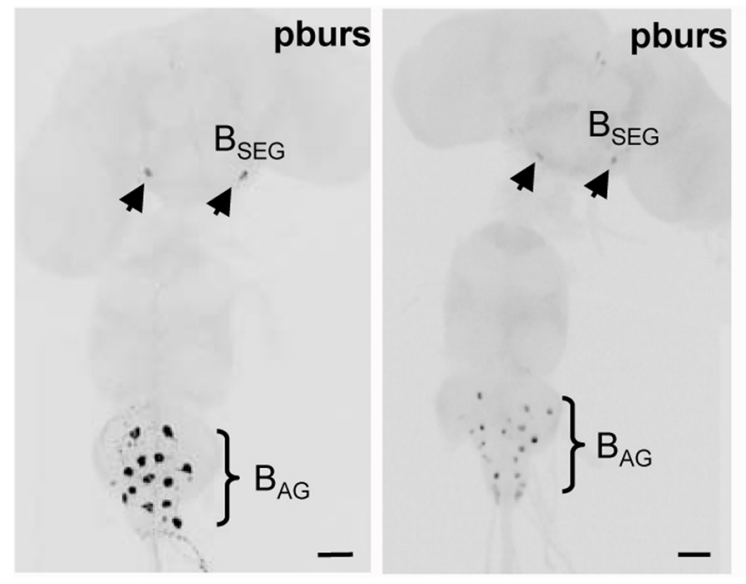

B

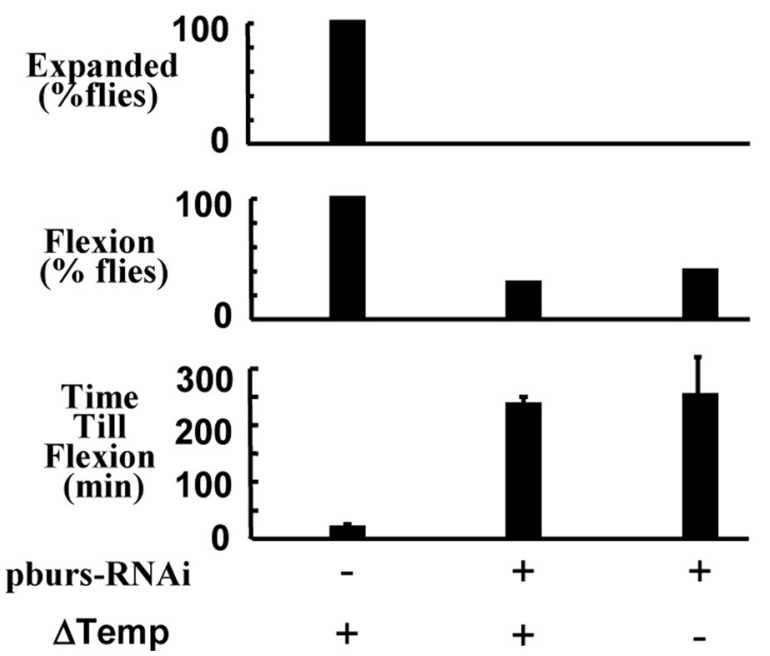

C

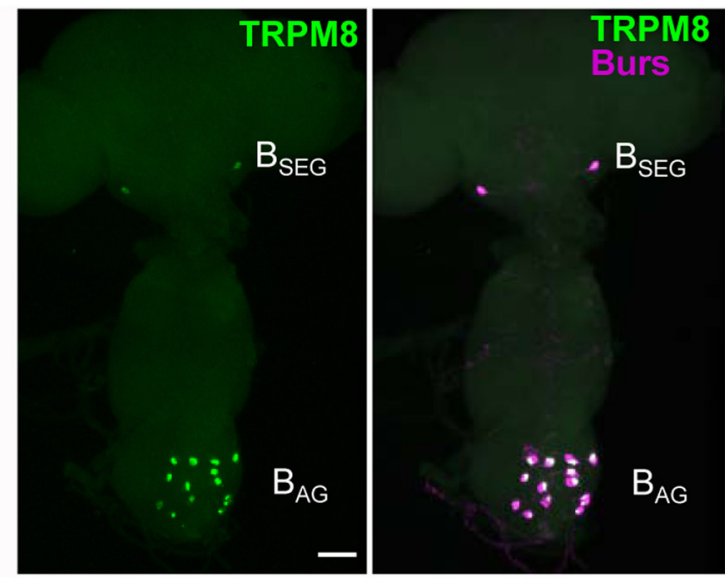

Burs-Gal4>UAS-TRPM8

D

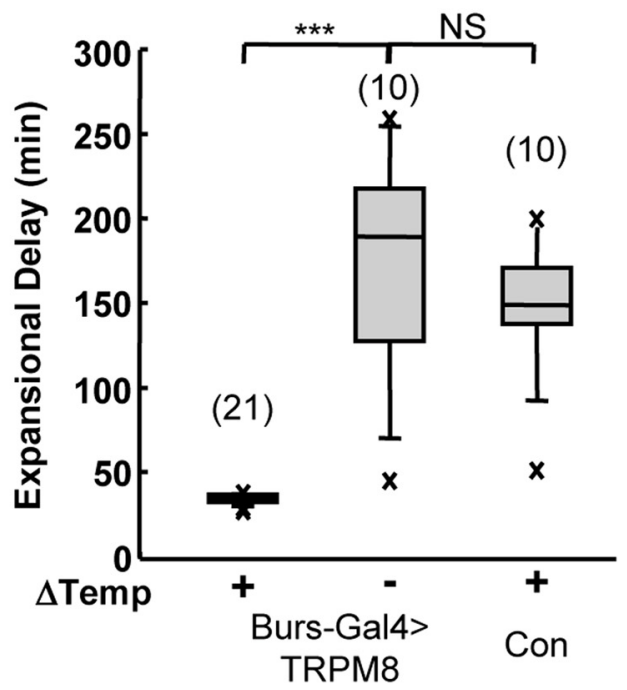

Figure 1. Bursicon and bursicon-expressing neurons are critical for the induction of wing expansion in adverse environments. $\boldsymbol{A}$, CNS whole mounts from newly eclosed flies expressing either TRPM8 alone (left) or TRPM8 plus an RNAi construct directed against the bursicon subunit pburs (right) in CCAP-expressing neurons were labeled with an anti-pburs antibody. pburs-RNAi expression substantially reduced anti-pburs immunostaining in both groups of bursicon-expressing neurons, the $B_{S E G}$ (arrowheads) and the $B_{A G}$ (brackets). Scale bar, $50 \mu$ m. $B$, Bar graphs showing that flies expressing pburs-RNAi did not expand their wings (top). Unlike control flies not expressing pburs-RNAi, $30 \%$ of flies in which pburs levels were knocked down exhibited expansional behavior (middle), but only after environmental delays in the time till abdominal flexion (bottom), even when the CCAP-expressing neurons were stimulated ( $\Delta$ temperature). $C$, Burs-Gal4 drives UAS-TRPM8 expression in both subsets of bursicon-expressing neurons, the $B_{A G}$ and the $B_{S E G}$ as revealed by double-labeling with anti-burs (magenta) and anti-TRPM8 (green) immunolabeling. Scale bar, 50 $\mu \mathrm{m} . \boldsymbol{D}$, Box plots show that under adverse conditions, a $15 \mathrm{~min}$ temperature shift to $18^{\circ} \mathrm{C}$ from $25^{\circ} \mathrm{C}(\Delta$ Temp) rapidly induced wing expansion in Burs-Gal $4>\mathrm{TRPM} 8$ flies ( + ) compared with control animals either of the same genotype and not subjected to temperature shift (-) or lacking the Burs-Gal4 driver [control (Con)]. The no-temperature-shift control plot includes two animals that tonically flexed their abdomens, but did not fully expand their wings. As noted in Materials and Methods, this sometimes happens after prolonged delays. In these cases, "Expansional Delay" indicates the time until termination of abdominal flexion. ${ }^{* *} p<0.001$; NS, not significant $(p>0.05)$; evaluated by $t$ test. The number of animals in each group is in parentheses above each plot. Error bars are SD.

is accomplished by forcing blood into the folded wing pads. The increase in blood pressure required for expansion results from the simultaneous execution of two motor patterns, one an adapted feeding behavior in which the fly swallows air, and the other a tonic radial constriction and downward flexion of the abdomen that lasts $\sim 15$ min (Denlinger and Zdarek, 1994; Baker and Truman, 2002; Peabody et al., 2009). These two motor patterns, which serve together to drive blood out of the abdomen and into the wings, must be accompanied by physiological changes in wing properties for expansion and subsequent hardening to occur (Honegger et al., 2008).

If newly emerged flies find themselves in an adverse environment, something that likely happens regularly in the wild and can be accomplished in the laboratory by placing them in a tightly confining chamber, they will search for a more suitable perch and delay wing expansion for up to several hours. Even in an inhibitory environment, however, perching and subsequent wing expansion can be forced by stimulating a set of $\sim 50$ central neurons that express the neuropeptide CCAP (Peabody et al., 2009). Although CCAP itself plays no known role in wing expansion, a subset of the CCAP-expressing neurons coexpresses the heterodimeric hormone bursicon, which is an essential molecular determinant of that process (Luan et al., 2006b). Flies with genetic lesions in the bursicon signaling pathway fail to expand their wings, as do animals in which the bursicon-expressing neurons have been suppressed (Baker and Truman, 2002; Dewey et al., 2004; Peabody et al., 2008).

Given bursicon's critical role in wing expansion, we reasoned that at least part, and perhaps all, aspects of the induction of wing expansion by stimulation of the CCAP-expressing neurons was 

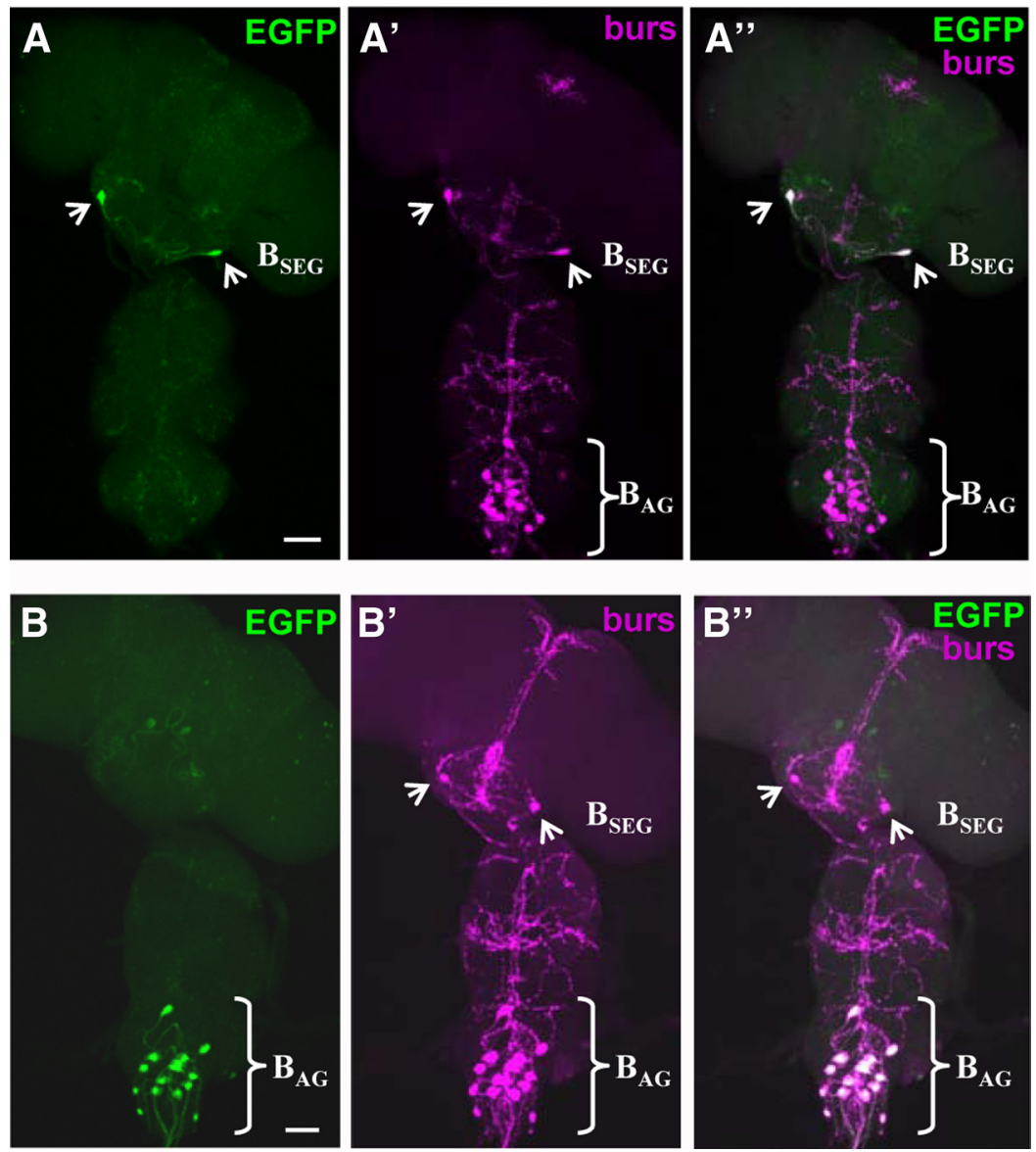

Figure 2. UAS transgenes can be selectively targeted to the $B_{\mathrm{SEG}}$ and $\mathrm{B}_{\mathrm{AG}}$ neurons. $\boldsymbol{A}, \boldsymbol{B}$, UAS transgene expression (green, UAS-EGFP) can be targeted to the two subsets of bursicon-expressing neurons (magenta, anti-burs) using the $B_{\mathrm{SEG}_{\mathrm{G}}}$-specific (i.e., $\mathrm{ET}^{\mathrm{VP16AD}}-99 \cap$ Burs-Gal4 ${ }^{\mathrm{DBD}}-\mathrm{U} 6 \mathrm{~A} 1 ; \boldsymbol{A}$ ) or the $\mathrm{B}_{\mathrm{AG}}$-Specific (i.e., ET ${ }^{\mathrm{VP} 16 \mathrm{AD}}-\mathrm{N} 9 \mathrm{~A} 88 \mathrm{~A} \cap$ Burs-Gal4 ${ }^{\mathrm{DBD}}-\mathrm{U} 6 \mathrm{~A} 1 ; \boldsymbol{B}$ ) hemidriver combinations. Images are volume-rendered fluorescent confocal micrographs of CNS whole mounts. Scale bars, $50 \mu \mathrm{m}$. $\boldsymbol{A}^{\prime}, \boldsymbol{B}^{\prime}$, The corresponding patterns of anti-bursicon $\alpha$-subunit labeling for the preparations shown in $\boldsymbol{A}$ and $\boldsymbol{B}$, respectively. $\boldsymbol{A}^{\prime \prime}, \boldsymbol{B}^{\prime \prime}$, Merged images of the patterns of EGFP and anti-bursicon labeling for the two preparations.

mediated by this molecule. To directly test the role of bursicon in the induction of wing expansion, we selectively reduced bursicon levels in these neurons by RNAi-mediated knock-down of the essential bursicon subunit pburs (Fig. 1A) (Luo et al., 2005; Mendive et al., 2005) and examined the ability of neuronal stimulation to induce expansion. Newly emerged flies were placed in a confined environment, and the CCAP-expressing neurons, which expressed the cold-activated channel TRPM8 in addition to the pburs-RNAi construct, were then selectively stimulated by briefly shifting the animals from $25^{\circ} \mathrm{C}$ to $18^{\circ} \mathrm{C}$. To assess induction, we scored animals for persistent abdominal constriction and downward flexion (henceforth referred to as abdominal flexion), one of the two behavioral signatures of wing expansion. Whereas all control animals rapidly flexed their abdomens in response to activation of the CCAP-expressing neurons, and expanded their wings as previously reported (Peabody et al., 2009), none of the animals expressing pburs-RNAi expanded (Fig. $1 \mathrm{~B}$, top), confirming the essential role of bursicon in that process. Wing expansion behavior was also eliminated in most flies, though approximately one-third of the stimulated animals did exhibit tonic abdominal flexion. However, they did so only after environmental delays similar to those of flies in which the CCAPexpressing neurons were not activated. We conclude that bursicon is required for the command-like function of the CCAP neurons, and that bursicon levels must exceed some threshold to be able to trigger wing expansion behavior in the face of environmental inhibition.

To directly determine whether the bursicon-expressing neurons alone could command wing expansion, we selectively targeted expression of TRPM8 to the bursicon-expressing neurons using the Burs-Gal4 driver (Fig. 1C) (Peabody et al., 2008) and stimulated them as before by briefly shifting animals confined within an inhibitory environment from $25^{\circ} \mathrm{C}$ to $18^{\circ} \mathrm{C}$. We found that activation of the bursicon-expressing neurons quickly forced expansion compared with control animals not subjected to cold or lacking the Burs-Gal4 driver (Fig. 1D). The effect is essentially identical to that produced by stimulation of the CCAP-expressing neurons and demonstrates that the bursiconexpressing neurons alone can command wing expansion.

\section{The $B_{\text {SEG }}$ neurons have command-like function}

The bursicon-expressing neurons consist of two anatomically distinct groups, which have been differentially implicated in mediating the somatic and behavioral aspects of wing expansion (Luan et al., 2006b; Peabody et al., 2008). A set of 14 bilaterally paired cells in the abdominal ganglion (i.e., the $\mathrm{B}_{\mathrm{AG}}$; Fig. $1 A, C$ ) are known to release bursicon into the blood where it is thought to promote, first, plasticization and, later, tanning of the wing cuticle (Honegger et al., 2008), whereas a single pair of cells in the subesophageal ganglion (i.e., the $\mathrm{B}_{\mathrm{SEG}}$ ) have been proposed to act centrally to govern the motor program underlying wing expansion based on indirect evidence. To directly assess the function of the $\mathrm{B}_{\mathrm{SEG}}$ in promoting the wing expansion motor program, we first used the Split Gal4 system (Luan et al., 2006a) to create hemidriver combinations that permitted selective transgene targeting to the $\mathrm{B}_{\mathrm{SEG}}$. Screening a library of enhancer-trap VP16AD hemidriver lines with a Burs ${ }^{\text {Gal4DBD }}$ hemidriver, which expresses the Gal4 DNAbinding domain specifically in the bursicon-expressing neurons, yielded lines that permit UAS-EGFP expression in newly eclosed adults in the $\mathrm{B}_{\mathrm{SEG}}$ (Fig. $2 A-A^{\prime \prime}$ ) or the $\mathrm{B}_{\mathrm{AG}}$ (Fig. $2 B-B^{\prime \prime}$ ).

We used these lines to activate TRPM 8 in either the $B_{\mathrm{SEG}}$ or $\mathrm{B}_{\mathrm{AG}}$ in animals placed in an inhibitory environment. We found that only stimulation of the $\mathrm{B}_{\mathrm{SEG}}$ induced the abdominal motor pattern characteristic of wing expansion (Fig. $3 A$; Table 1). In contrast, stimulation of the $\mathrm{B}_{\mathrm{AG}}$ alone did not accelerate performance of the wing expansion motor program, which was executed only after a delay of $2-3 \mathrm{~h}$, similar to controls. This is consistent with previous results indicating that these neurons have no role in governing behavior, but instead are responsible for bursicon release into the blood. Indeed, Western blot analysis of blood obtained from $\mathrm{B}_{\mathrm{AG}}>\mathrm{TRPM} 8$ animals confirmed the presence of bursicon in the blood after a temperature shift to $18^{\circ} \mathrm{C}$ (Fig. 3B, top), though interestingly the amount of hormone 
released was reduced relative to that seen under conditions of normal expansion. This stimulated release of hormone was likely responsible for the notable change in wing morphology that followed $\mathrm{B}_{\mathrm{AG}}$ activation, in which the wings became malleable and partially unfolded in response to occasional grooming by the hindlegs (Fig. 3C, left).

Surprisingly, stimulation of the $\mathrm{B}_{\mathrm{SEG}}$ induced not just the wing expansion motor program, which alone is insufficient for expansion (Luan et al., 2006b), but induced full wing expansion on time scales similar to those of animals in which all CCAP- or bursicon-expressing neurons were stimulated (Fig. $3 A, C$, right). The $\mathrm{B}_{\mathrm{SEG}}$ thus retain the full command potential of the larger cell groups in inducing wing expansion. Consistent with this, we observed that $\mathrm{B}_{\mathrm{SEG}}$ stimulation induced robust bursicon secretion from the $\mathrm{B}_{\mathrm{AG}}$ as assayed by Western blot (Fig. $3 B$, bottom; Table 1). To directly confirm that the $\mathrm{B}_{\mathrm{AG}}$ were the source of the released hormone, we monitored the depletion of bursicon immunoreactivity (burs-IR) from the abdominal nerves, which contain the $\mathrm{B}_{\mathrm{AG}}$ axons and act as neurohaemal release sites (Peabody et al., 2008). We found that the abdominal nerves of $\mathrm{B}_{\mathrm{SEG}}>\mathrm{TRPM} 8$ animals had $\sim 40 \%$ lower burs-IR after $B_{\text {SEG }}$ stimulation compared with unstimulated control animals (Fig. $3 D, E$ ). We conclude that $\mathrm{B}_{\mathrm{SEG}}$ activation causes bursicon release into the blood from the $\mathrm{B}_{\mathrm{AG}}$, thus accounting for the ability of $\mathrm{B}_{\mathrm{SEG}^{-}}$ stimulated animals to plasticize and tan normally (Fig. 3C, right) despite the lack of direct $\mathrm{B}_{\mathrm{AG}}$ activation by TRPM8.

\section{The $\mathrm{B}_{\text {SEG }}$ are required for wing expansion in adverse environments} Our TRPM8 stimulation experiments suggest that the $\mathrm{B}_{\mathrm{SEG}}$ can orchestrate the entire wing expansion process, and thus effect the expansion decision even in the face of environmental perturbation. To examine whether these neurons are normally required for that function and whether their activity is essential for activation of the $B_{A G}$, we selectively inhibited the $\mathrm{B}_{\mathrm{SEG}}$ using the potent inward rectifier $\mathrm{K}^{+}$channel, Kir2.1 (Baines et al., 2001; Paradis et al., 2001) and evaluated the behavioral consequences of this manipulation. Observation of $\mathrm{B}_{\mathrm{SEG}^{-}}$ suppressed flies in the inhibitory environment revealed that these animals neither expanded their wings nor initiated the phase of tonic abdominal flexion that normally drives expansion $(n=10)$, thus providing strong evidence that the $\mathrm{B}_{\mathrm{SEG}}$ are required for performance of wing expansion behavior. A puzzling observation, however, was that the wing expansion deficits seen in the inhibitory environment were largely absent in unperturbed siblings that expanded in the food vial in which they had pupariated (Fig. 4A, left). Most of the unperturbed animals exhibited only mi-
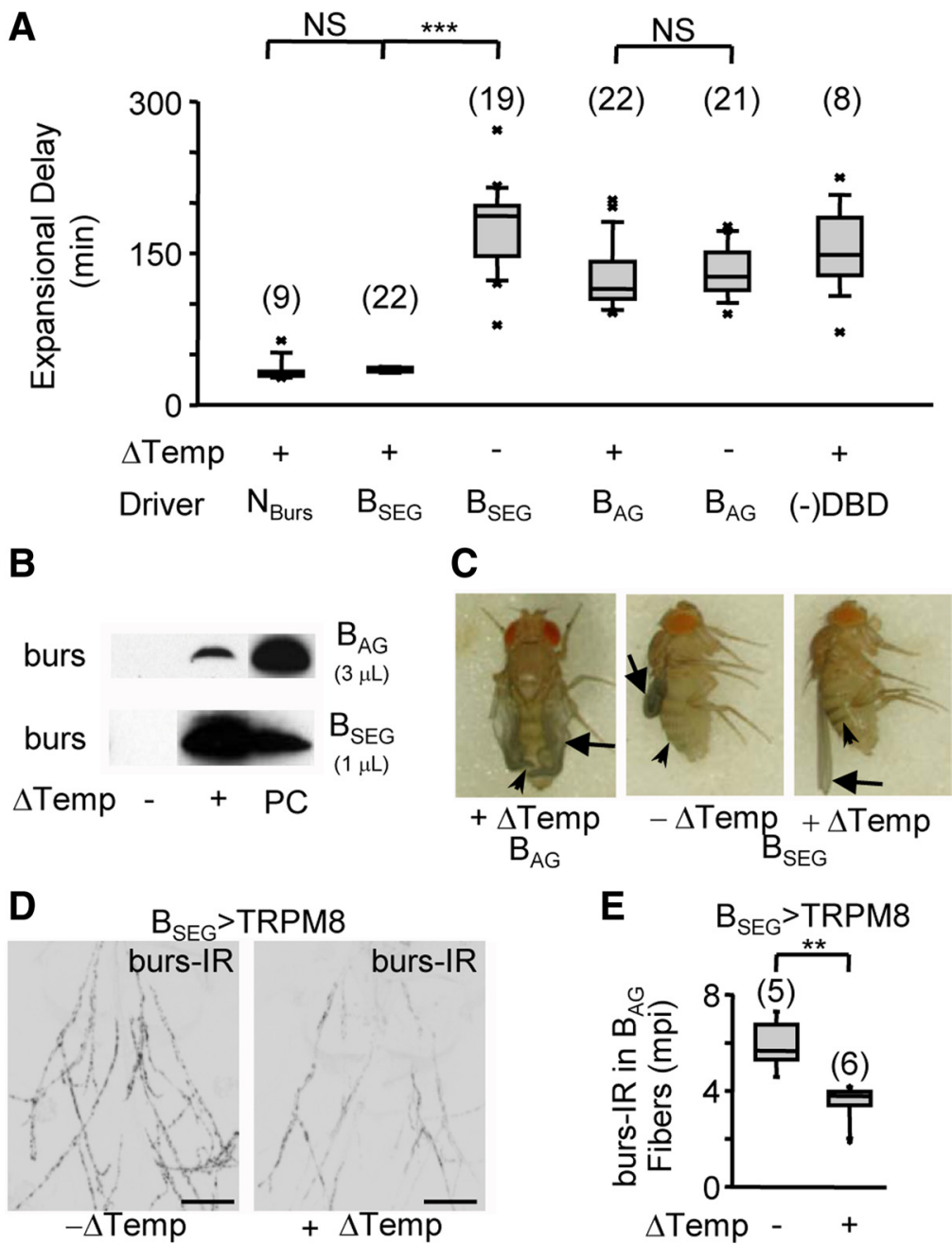

Figure 3. The $B_{S E G}$ neurons command wing expansion in Drosophila. $A$, Box plots showing the time required to complete stimulation ( $\Delta$ temperature). (-)DBD, controls lacking the Burs ${ }^{\text {GaIDBD }}$-U6A1 hemidriver. As noted in the legend of Figure 1, some fles that attempted expansion after prolonged delays failed to expand their wings, in which case the expansional delay represents rs; the results of $t$ test comparisons between groups are indicated by brackets [NS, not significant $(p>0.05)$; $\left.{ }^{* * *} p<0.001\right]$. $\boldsymbol{B}$ (i.e., anti-burs immunostaining) resulting from stimulation ( $\Delta$ temperature) of the immunostained for bursicon using anti-burs antibodies. Scale bars, $50 \mu \mathrm{m}$. $\boldsymbol{E}$, Box plot showing quantified burs-IR data from abdominal nerves of the indicated number of animals of each kind shown in $\boldsymbol{D}$, demonstrating release of bursicon from these nerve in response to $B_{S E G}$ stimulation. mpi; Mean pixel intensity (background-subtracted). ${ }^{* *} p<0.01$ by $t$ test. Error bars are SEM.

nor wing abnormalities such as mild wrinkling and splaying, and one-third of those with fully expanded wings were capable of flight $(n=14 / 43)$. Examination of the patterns of Kir2.1 expression and anti-bursicon immunolabeling in these animals confirmed that Kir2.1 was expressed in the $\mathrm{B}_{\mathrm{SEG}}$ and that no obvious compensatory changes in the bursicon network occurred, in that the full complement of $\mathrm{B}_{\mathrm{AG}}$ neurons were present (data not shown). In addition, ablation experiments confirmed that the absence of wing expansion deficits was not simply due to incomplete suppression of the $B_{\mathrm{SEG}}$ neurons by Kir2.1, as similar results were observed when the $\mathrm{B}_{\mathrm{SEG}}$ were eliminated using the proapoptotic gene hid (data not shown).

The differences in wing phenotype observed in $\mathrm{B}_{\mathrm{SEG}^{-}}$ suppressed flies allowed to expand in a large vial as opposed to a small chamber strongly suggested that environmental factors 
Table 1. Summary of manipulations and results

\begin{tabular}{|c|c|c|c|c|c|}
\hline \multirow[b]{2}{*}{ Cells manipulated/phenotype } & \multirow{2}{*}{$\begin{array}{l}\text { Activation (TRPM8) } \\
\text { Strong perturbation }\end{array}$} & \multicolumn{3}{|c|}{ Suppression (Kir2.1) } & \multirow{2}{*}{$\begin{array}{l}\text { Knockdown (pburs-RNAi } \\
\text { No perturbation }\end{array}$} \\
\hline & & No perturbation & Mild perturbation & Strong perturbation & \\
\hline \multicolumn{6}{|l|}{$B_{S E G}$} \\
\hline Unexpanded wings (\% flies) & $0 \%$ & $2 \%$ & $78 \%$ & $100 \%$ & \\
\hline Air swallowing & - & Little & No & - & \\
\hline Abdominal flexion & Yes, acute & No & No & No & \\
\hline \multicolumn{6}{|l|}{ Bursicon release } \\
\hline $\mathrm{B}_{\mathrm{AG}}$ & High & Yes & - & - & \\
\hline$B_{S E G}$ & - & No & - & - & \\
\hline Tanning & Yes & Yes & № & № & \\
\hline \multicolumn{6}{|l|}{$B_{A G}$} \\
\hline Unexpanded wings (\% flies) & $22 \%$ & $2 \%$ & $17 \%$ & $71 \%$ & $47 \%$ \\
\hline Air swallowing & - & Yes & - & - & Yes \\
\hline Abdominal flexion & Yes, but delayed & Yes & Yes & Yes & $2 \times$ \\
\hline \multicolumn{6}{|l|}{ Bursicon release (by IR) } \\
\hline$B_{A G}$ & Low & - & - & - & - \\
\hline $\mathrm{B}_{\mathrm{SEG}}$ & - & - & - & - & - \\
\hline Tanning & Yes & No & № & - & - \\
\hline
\end{tabular}

The table summarizes the effects of the three major manipulations performed: electrical activation or suppression of the individual groups of bursicon-expressing neurons (i.e. the $B_{S E G}$ and the $B_{A G}$ ) or block of bursicon formation in the $B_{A G}$ by knocking down expression of the bursicon subunit pburs. Column subheadings indicate the environmental conditions under which each manipulation was performed. The effects analyzed include: wing expansion deficits (reported here as the percentage of flies with unexpanded wings), behavioral deficits (in either air swallowing or tonic abdominal flexion), neuroendocrine deficits (in terms of bursicon release, measured directly by either immunoblot or by depletion of bursicon immunoreactivity from $B_{A G}$ or $B_{S E G}$ fibers), and cuticle tanning. —, Not determined.

were important to success in expansion. To systematically test the role of environment, we therefore compared the behavior of single animals that emerged into a large food vial and remained completely unperturbed with those that experienced gentle perturbation immediately after emergence, in the form of transfer to a new food vial. Although the latter manipulation was without effect on control flies, it prevented most $\mathrm{B}_{\mathrm{SEG}}$-suppressed flies $(n=21 / 27)$ from expanding (Fig. $4 \mathrm{~A}$, middle vs right; Table 1$)$.

Consistent with their failure to expand, these gently perturbed animals also did not tonically flex their abdomens. Interestingly, this was also true of flies that expanded in the absence of environmental perturbation (Fig. $4 B, C$; Table 1 ). In addition, the latter flies exhibited impaired air swallowing, with most males swallowing little to no air and females swallowing, on average, $16 \%$ of the amount of air swallowed by control females (Fig. 4D; Table 1). The normal motor patterns required for wing expansion are thus largely or completely absent in $\mathrm{B}_{\mathrm{SEG}}$-suppressed animals, regardless of environmental circumstances, indicating that the $\mathrm{B}_{\mathrm{SEG}}$ are not only sufficient, but also necessary for the initiation and/or maintenance of these behaviors. Careful observation revealed that the ability of $\mathrm{B}_{\mathrm{SEG}}$-suppressed animals to expand in noninhibitory environments despite these deficits derives from their reliance on an alternate behavioral strategy. These animals expand their wings by vigorously pulsing their abdomens in both longitudinal and lateral dimensions, while repeatedly stroking their hindlegs backwards across their wings (Fig. 4C). Such wing stroking was occasionally observed in control animals, but almost always immediately after expansion when it appeared to transiently splay the wings (data not shown). Wing grooming may thus play an auxiliary role in expansion in normal flies, but in $\mathrm{B}_{\mathrm{SEG}}$-suppressed flies it appears to be essential.

Because the wings of $\mathrm{B}_{\mathrm{SEG}}$-suppressed animals were sufficiently plasticized to expand in response to repeated stroking, and because expansion in these animals was followed by tanning (Fig. $4 \mathrm{~A}$, left, arrowhead), we reasoned that wing grooming must be coordinated with bursicon release from the $\mathrm{B}_{\mathrm{AG}}$. To determine whether unperturbed $\mathrm{B}_{\mathrm{SEG}}$-suppressed flies do indeed release bursicon at the time of wing expansion, we measured bursicon immunoreactivity in the abdominal nerves both before wing expansion (i.e., immediately after emergence) and after its comple- tion. We found that burs-IR levels were, on average, 35\% lower in animals that had expanded (Fig. $4 E, F$ ), indicating substantial release of the hormone from $\mathrm{B}_{\mathrm{AG}}$ axons. In contrast, we detected no significant difference in burs-IR in the axons of the suppressed $\mathrm{B}_{\mathrm{SEG}}$ neurons (Fig. 4F; Table 1), consistent with the electrical silencing of these cells.

\section{$B_{\text {SEG }}$ activation is independent of the $B_{A G}$}

The observation that the silenced $\mathrm{B}_{\mathrm{SEG}}$ do not release detectable bursicon suggests that $\mathrm{B}_{\mathrm{SEG}}$-derived bursicon may be necessary for the normal execution of wing expansion motor patterns. To directly demonstrate this, we attempted to eliminate bursicon production in the $\mathrm{B}_{\mathrm{SEG}}$ using RNAi-mediated pburs-knockdown but found that this manipulation, which necessitated the coexpression of UAS-dicer-2, was not fully effective. However, we were able to selectively eliminate pburs expression in the $\mathrm{B}_{\mathrm{AG}}$ neurons by this means (data not shown) and used this manipulation, together with Kir2.1-mediated suppression of excitability, to examine the molecular and cellular contribution of the $\mathrm{B}_{\mathrm{AG}}$ to wing expansion. Consistent with previous results, we found that both $\mathrm{B}_{\mathrm{AG}}$ suppression and pburs knockdown within this cell group left behavioral performance intact (Fig. 5A, $B$; Table 1). Interestingly, however, most flies in which $\mathrm{B}_{\mathrm{AG}}$ pburs expression was blocked exhibited a robust second bout of abdominal flexion, a phenomenon that was also seen in attenuated form in some $\mathrm{B}_{\mathrm{AG}}>$ Kir2.1 animals. While the first bout of flexion in $\mathrm{B}_{\mathrm{AG}}>$ pburs-RNAi animals was similar to that of control animals in duration and time of onset relative eclosion (Fig. 5C), the second bout lasted approximately half as long as the first ( $7 \pm 2 \mathrm{~min}$ vs $12 \pm 4 \mathrm{~min}, \mathrm{SD} ; n=7)$, and typically followed it after an interval of $13 \mathrm{~min}$ ( $\pm 2 \mathrm{~min}, \mathrm{SD})$. These results confirm that $\mathrm{B}_{\mathrm{AG}}$-derived bursicon is clearly not necessary for the performance of wing expansion behaviors, but suggest that it plays a role in negatively regulating them.

In addition, we confirmed that suppression of the $B_{A G}$ substantially inhibits bursicon release into the hemolymph, as indicated by the failure to tan within $3 \mathrm{~h}$ of eclosion (Fig. $5 E$, left vs middle). Surprisingly, suppression by Kir2.1 appeared not to be complete, in that during the period of persistent abdominal flexion $\mathrm{B}_{\mathrm{AG}}>$ Kir2.1, animals succeeded in partially unfolding their wings under the combined influence of pres- 
A

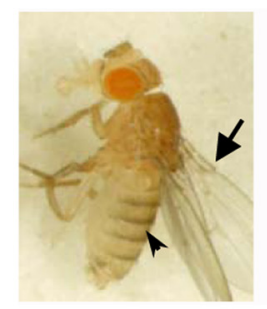

$\mathrm{B}_{\mathrm{SEG}}>\mathrm{Kir} 2.1$

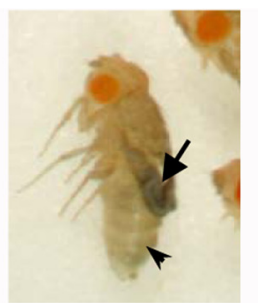

$\mathrm{B}_{\mathrm{SEG}}>\mathrm{Kir} 2.1$

Mild

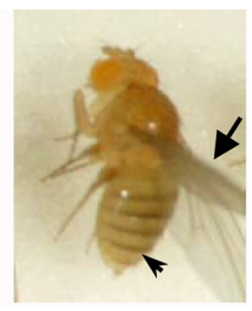

Control

Mild
B

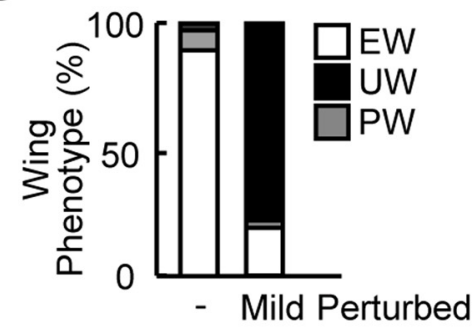

Perturbed No

D

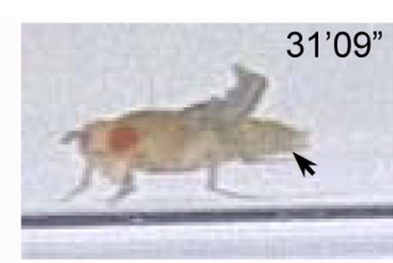

C

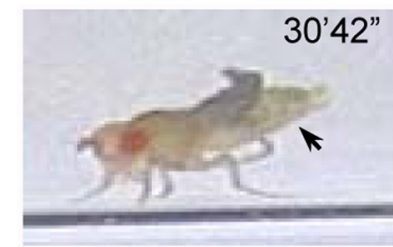

31'23"
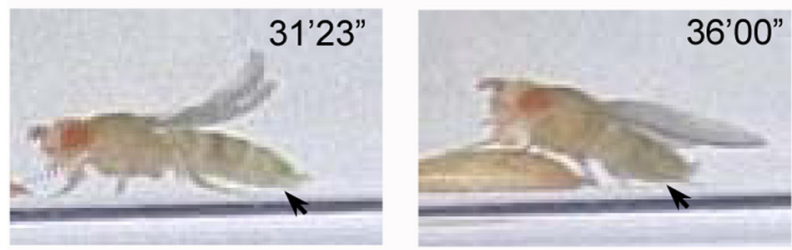

E Abdominal Nerves in $B_{\text {SEG }}>$ Kir2.1 Flies

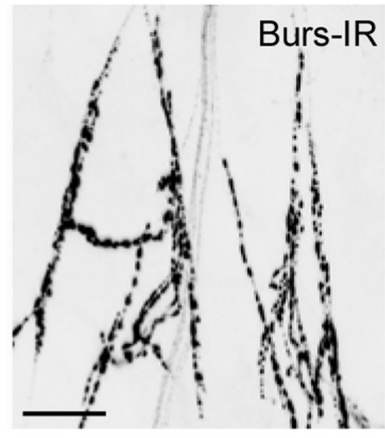

Pre-Expansion

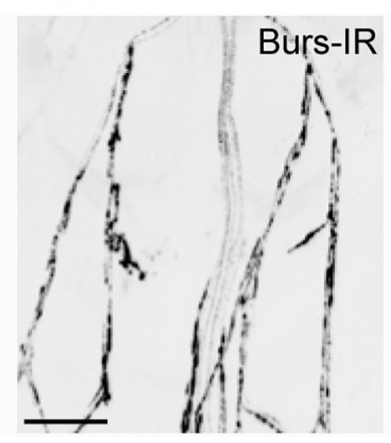

Post-Expansion
F

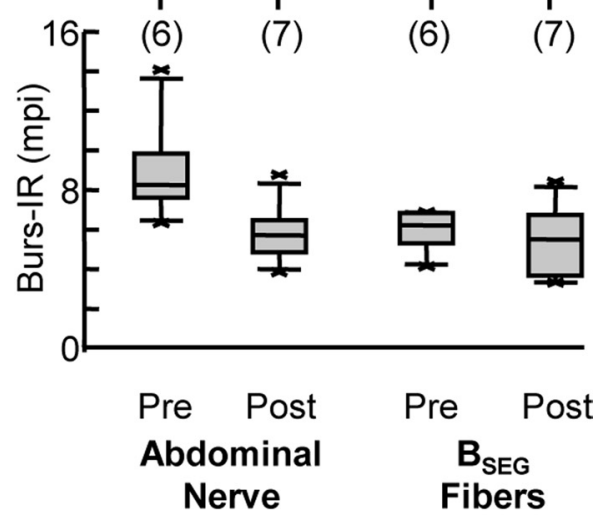

Figure 4. $B_{S E G}$ suppression inhibits wing expansion motor patterns and blocks expansion in adverse environments. $\boldsymbol{A}$, Tanning (arrowhead) and wing expansion (arrow) are relatively normal in $B_{S E G}>$ Kir2.1 flies expanding unperturbed (left), but impaired in animals experiencing even mild perturbation (middle) compared with controls lacking the $B_{S E G}$ hemidriver (right). $\boldsymbol{B}$, Wing expansion is differentially impaired in $B_{S E G}>$ Kir2.1 flies in unperturbed ( - ) and mildly perturbing (Mild) environments. EW, Expanded wings, UW, unexpanded wings; PW, partially expanded wings. $C$, Video frames of a $B_{S E G}>$ Kir2.1 fly expanding unperturbed showing abdominal movement (arrows) but not persistent flexion during the course of successful expansion. Time points are as indicated. $D$, Unperturbed $B_{S E G}>$ Kir2.1 flies $\left(B_{S E G}\right)$ swallow significantly less air during expansion than flies lacking the $B_{S E G}$ hemidriver (control). $-\phi$, males; $O_{\text {, females. }}^{* * *} p<0.001$ by $t$ test. $\boldsymbol{E}$, Abdominal nerves from unperturbed $B_{\mathrm{SEG}}>$ Kir2.1 flies immediately after eclosion (i.e., pre-expansion; left) or expansion (i.e., post-expansion; right) immunostained for bursicon using anti-burs antibodies. Scale bars, $50 \mu \mathrm{m}$. $\boldsymbol{F}$, Box plots (left) show quantified burs-immunoreactivity data from abdominal nerves of each kind shown in $\boldsymbol{E}$, demonstrating release of bursicon from the nerves in the absence of $B_{S E G}$ activity. In contrast, box plots on the right show no change in burs-IR in $B_{S E G}$ fibers in the second thoracic ganglion ( $B_{S E G}$ Fibers), confirming absence of $B_{S E G}$ activity. Number of samples analyzed for each plot is indicated in parentheses. ${ }^{*} p<0.05$; NS, not significant ( $p>$ $0.05)$, as determined by $t$ test. Error bars are SD.

sure and wing stroking by the hindlegs (Fig. $5 D, E$ ). This effect was relatively insensitive to mild perturbation (Fig. 5D) and was considerably less evident in animals subjected to pburs knockdown in the $\mathrm{B}_{\mathrm{AG}}$, many of which retained completely unexpanded wings (Fig. 5D,E, right). Kir2.1-mediated suppression thus appears to provide a slightly less effective block of bursicon release into the hemolymph than pburs knockdown in the $\mathrm{B}_{\mathrm{AG}}$, which may also account for the behavioral differences described above. However, both manipulations confirm that the $\mathrm{B}_{\mathrm{AG}}$ are the principal source of bursicon re- leased into the hemolymph and play an essential role in insuring normal wing tanning and morphology.

\section{Discussion}

Here we functionally dissect the previously described command system for wing expansion in Drosophila (Peabody et al., 2009) and find that stimulation of a single pair of neurons, the $\mathrm{B}_{\mathrm{SEG}}$, is capable of commanding the entire wing expansion program under environmental conditions that would otherwise inhibit it. Because this program requires the simultaneous execution of at 

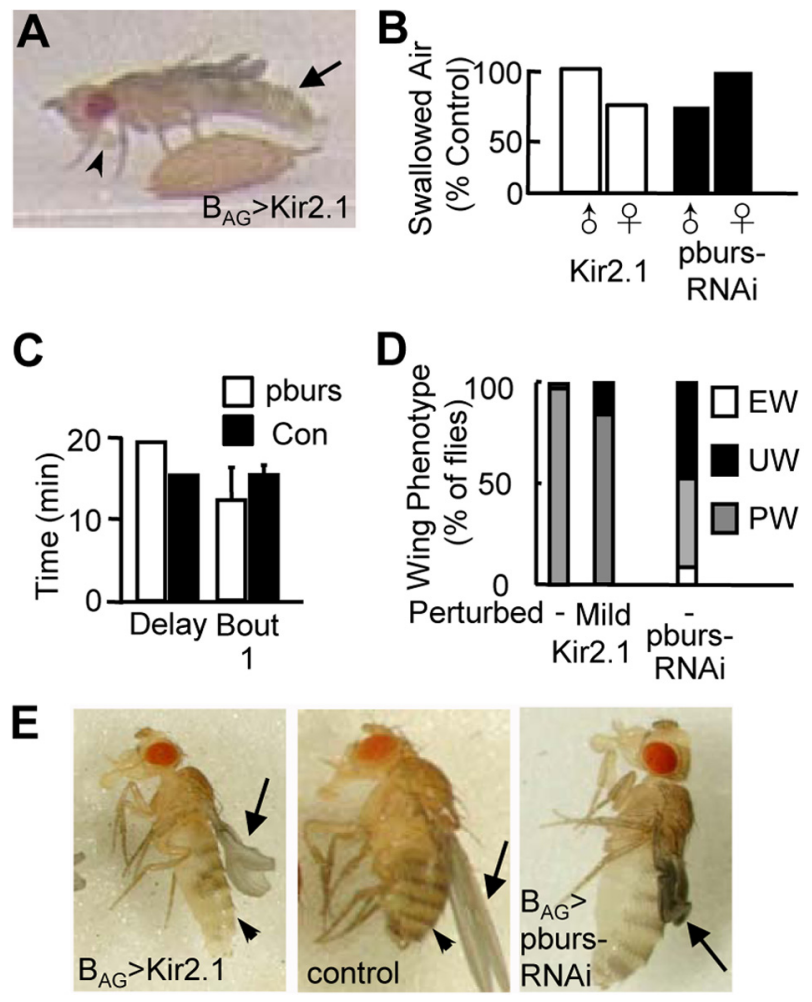

Figure 5. $B_{A G}$ suppression blocks somatic, but not behavioral, aspects of wing expansion. $A$, Video frame of a $B_{A G}>$ Kir2.1 fly showing that the execution of abdominal flexion (arrow) and proboscis extension required for air swallowing (arrowhead) are normal. $B$, Both $B_{A G}>$ Kir2.1 (left) and $B_{A G}>$ pburs-RNAi (right) flies swallow substantial amounts of air during the period of sustained abdominal flexion relative to matched controls (i.e., either flies lacking the DBD hemidriver or the UAS-pburs-RNAi transgene, respectively). - -, males; ,, females. C, Bar graphs showing the median time from eclosion to the onset of the first bout sustained abdominal flexion (Delay) and the average duration of the first bout (Bout 1 ) in $B_{A G}>$ pburs-RNAi flies $(n=7)$ versus matched controls (Con) lacking the UAS-pburs-RNAi transgene $(n=9)$. Error bars are SD. $\boldsymbol{D}$, Wing expansion deficits observed in $\mathrm{B}_{\mathrm{AG}}>$ Kir2.1 flies in noninhibitory ( - ) and inhibitory (+) environments are similar (left) and somewhat less severe than those observed in $B_{A G}>$ pburs-RNAi flies (right). EW, Expanded wings, UW, unexpanded wings; PW, partially expanded wings. $\boldsymbol{E}$, Left and middle, Wing expansion (arrow) and cuticle tanning (arrowhead) are impaired in $B_{A G}>$ Kir2.1 animals (left; note reduced pigmentation), relative to controls lacking the $B_{A G}$ hemidriver (middle). Right, the wings (arrow) of $B_{A G}>$ pburs-RNAiflies typically undergo little to no expansion during abdominal flexion.

least two motor patterns and the hormonal release of bursicon from the $\mathrm{B}_{\mathrm{AG}}$ neurons, we conclude that $\mathrm{B}_{\mathrm{SEG}}$ stimulation coordinates the various processes required for expansion. Genetic evidence (Baker and Truman, 2002; Dewey et al., 2004), along with the RNAi-mediated knockdown results presented here, indicates that the neuromodulator bursicon is the primary effector in orchestrating the various aspects of wing expansion. Thus, our results illustrate how a neuromodulator, released from widely ramifying projection neurons, can orchestrate a complex response to environmental conditions within a simple decision circuit.

\section{The neuroarchitecture of the wing expansion decision}

The command-like function of the $\mathrm{B}_{\mathrm{SEG}}$ and their necessity for wing expansion in adverse environments suggests a critical role for these neurons in the decision-making network that governs wing expansion in Drosophila. A central question, however, is where in the hierarchy of the decision network these neurons lie. Our results, together, speak against the simplest possibility, namely that they are directly responsible for the wing expansion decision, receiving and integrating sensory inputs from the environment and executing the expansion decision by the release of bursicon. If this were the case, all effectors of wing expansion would necessarily lie downstream of the $\mathrm{B}_{\mathrm{SEG}}$, including the $\mathrm{B}_{\mathrm{AG}}$. While this interpretation is compatible with the effects of TRPM8-mediated activation of the $\mathrm{B}_{\mathrm{SEG}}$, it is inconsistent with our finding that the $\mathrm{B}_{\mathrm{AG}}$ become activated when the $\mathrm{B}_{\mathrm{SEG}}$ are suppressed, at least in noninhibitory environments. That the $\mathrm{B}_{\mathrm{SEG}}$ are likewise activated when the $\mathrm{B}_{\mathrm{AG}}$ are suppressed is a strong argument that both groups of bursicon-expressing neurons, which are coordinately activated during normal wing expansion, are regulated by a common activation path. The existence of such a path is underscored by the fact that $\mathrm{B}_{\mathrm{SEG}}{ }^{-}$ suppressed flies can expand their wings using non- $\mathrm{B}_{\mathrm{SEG}^{-}}$ mediated motor patterns (i.e., wing grooming), indicating that the drive to expand is represented by neurons outside the bursicon-expressing group. Although the identity of the putative activation path remains to be determined, it may include eclosion hormone-secreting neurons, which have been postulated to activate the wing expansion circuit (Truman, 2005) and are also required for wing expansion (McNabb et al., 1997).

If the $\mathrm{B}_{\mathrm{AG}}$ are not functionally downstream of the $\mathrm{B}_{\mathrm{SEG}}$, how does stimulation of the $\mathrm{B}_{\mathrm{SEG}}$ induce bursicon release into the blood? Although previous anatomical evidence suggested that the $\mathrm{B}_{\mathrm{AG}}$ might receive inputs from the $\mathrm{B}_{\mathrm{SEG}}$ (Peabody et al., 2008), the evidence presented here is more consistent with a model in which the $\mathrm{B}_{\mathrm{AG}}$ are indirectly activated by the $\mathrm{B}_{\mathrm{SEG}}$ through derepression of the activation pathway, which would account for the extreme environmental sensitivity of the wing expansion program when the $\mathrm{B}_{\mathrm{SEG}}$ are suppressed. Such a model would also predict distinct roles for the $\mathrm{B}_{\mathrm{SEG}}$ in regulating environmental inputs and wing expansion motor patterns. Just such a separation of function is suggested by the bursicon knock-down experiments presented in Figure $1 B$, where lowered levels of bursicon result in the inability to overcome environmental inhibition, but do not completely compromise the ability to execute wing expansion motor patterns.

If the $\mathrm{B}_{\mathrm{SEG}}$ feed back to modulate the environmental suppression of an activation path that governs both the $\mathrm{B}_{\mathrm{AG}}$ and $\mathrm{B}_{\mathrm{SEG}}$, it might account for how the wing expansion network resolves the conflict between the internally motivated need to expand (represented by the activation path) and the externally motivated need to delay expansion (represented by the environmental inhibition path). As a fly moves into a more favorable environment, activity in the inhibitory pathway should decrease, thus increasing activity in the activation path, which is amplified by disinhibition via a positive feedback loop through the $\mathrm{B}_{\mathrm{SEG}}$. With an appropriately set threshold, such a loop would promote the eventual concerted release of bursicon and the behavioral transition to wing expansion. The behavioral transition to larval ecdysis in Manduca and Drosophila is known to also rely on a positive feedback loop that drives the mutual release of ecdysistriggering hormone and eclosion hormone (Ewer et al., 1997; Kingan et al., 1997; Clark et al., 2004); we postulate that similar positive feedback switches with neuromodulatory outputs may be used in other decision networks.

\section{Compensatory mechanisms and environmental adaptation}

As indicated above, our results suggest that the $\mathrm{B}_{\mathrm{SEG}}$ serve distinct functions in modulating environmental inputs and governing motor output. With respect to motor output, the $\mathrm{B}_{\mathrm{SEG}}$ satisfy two of the major criteria required of command neurons (Kupfermann and Weiss, 1978): they are necessary for initiating or sus- 
taining the motor patterns normally required for wing expansion and are sufficient to elicit those patterns when stimulated. Given this role, it was surprising to find that the $\mathrm{B}_{\mathrm{SEG}}$ were dispensable for wing expansion in flies that remained completely unperturbed after eclosion.

What is the status of the $\mathrm{B}_{\mathrm{SEG}}$-independent wing expansion program? Because this compensatory program is coordinated with bursicon release from the $\mathrm{B}_{\mathrm{AG}}$, it is likely linked to the putative activation pathway. However, because the compensatory wing grooming patterns are not (or not necessarily) components of normal wing expansion, it is unclear how they are recruited in the absence of $\mathrm{B}_{\mathrm{SEG}}$ activity. It is possible that recruitment is due to rewiring of the wing expansion network, perhaps as a consequence of constitutive developmental suppression of the $\mathrm{B}_{\mathrm{SEG}}$. Alternatively, the compensatory wing-grooming program may result from a change in the pattern of activity within the existing network, for example by the unmasking of motor patterns normally suppressed by the $\mathrm{B}_{\mathrm{SEG}}$, or by the recruitment of backup motor patterns in response to proprioceptive input that indicates wing expansion is failing. A role for proprioception in wing expansion is likely given the observed recruitment of grooming during the expansional phase of $\mathrm{B}_{\mathrm{AG}^{-}}$as well as $\mathrm{B}_{\mathrm{SEG}}$-suppressed flies, but further work will be required to further elucidate the mechanistic basis of the compensatory program.

Regardless of mechanism, the dependence of the compensatory wing expansion program on the $\mathrm{B}_{\mathrm{AG}}$ underscores the essential nature of these neurons. Without them, the wings would neither fully expand nor harden regardless of the expansion program used. It is interesting to speculate that the $\mathrm{B}_{\mathrm{AG}}$ may thus represent an evolutionarily more basal component of the wing expansion process than the $\mathrm{B}_{\mathrm{SEG}}$, which insure expansion under conditions of environmental challenge. In this context, it is worth noting that only certain insect lineages, including cyclorrhaphan flies such as Drosophila, exhibit environmentally sensitive wing expansion programs as an evolutionary adaptation (Cottrell, 1964). Consistent with the proposed role of neuromodulation in circuit evolution (Katz and Harris-Warrick, 1999), this adaptation may have been accomplished by conscripting the $\mathrm{B}_{\mathrm{SEG}}$ neurons to modulate a novel environmentally governed inhibitory delay path. The compensatory wing expansion strategy used by flies in the absence of $\mathrm{B}_{\mathrm{SEG}}$ activity may correspondingly represent a vestige of an ancestral, hormonally governed and environmentally insensitive form of the wing expansion program. As more comparative studies become available, it will be interesting to see whether insects lacking environmentally adaptive wing expansion programs likewise lack $\mathrm{B}_{\mathrm{SEG}}$-like neurons. Currently, $\mathrm{B}_{\mathrm{SEG}}$ homologues have been described outside of Drosophila only in the hawkmoth, Manduca, which also can delay wing expansion (Truman, 1973; Dai et al., 2008).

\section{Neuromodulation and the integration of behavior}

Bursicon's action in orchestrating wing expansion bridges the known roles of neuromodulation in the regulation of motor rhythms (Dickinson, 1995; Nusbaum et al., 2001; Brezina, 2010) and physiological state (Pfaff et al., 2008) and illustrates how neuromodulators, released by a small set of neurons, can coordinate secretomotor and somatomotor outputs in response to environmental conditions. In pointing to a critical integrative role for neuromodulatory neurons in motor control, our work complements other recent findings, including the identification of octopaminergic neurons in the fly subesophageal ganglion that mediate male aggressiveness (Zhou and Rao, 2008) and peptidergic neurons in the mouse hypothalamus that regulate feeding
(Aponte et al., 2011). It is interesting in this regard to note that, like the neuromodulator-rich upper brainstem and hypothalamus in vertebrates (Swanson, 2000), the subesophageal ganglion has been implicated by brain lesion studies in the initiation and coordination of basic motor patterns in both insects and annelids (Ridgel and Ritzmann, 2005; Cornford et al., 2006). Based on the work presented here and previously (Brocard et al., 2005; Mesce et al., 2008; Mullins et al., 2011), it is interesting to speculate that vertebrates and invertebrates may share similar architectures of descending motor control in which neuromodulation acts as an organizing principle.

\section{References}

Aponte Y, Atasoy D, Sternson SM (2011) AGRP neurons are sufficient to orchestrate feeding behavior rapidly and without training. Nat Neurosci 14:351-355.

Baines RA, Uhler JP, Thompson A, Sweeney ST, Bate M (2001) Altered electrical properties in Drosophila neurons developing without synaptic transmission. J Neurosci 21:1523-1531.

Baker JD, Truman JW (2002) Mutations in the Drosophila glycoprotein hormone receptor, rickets, eliminate neuropeptide-induced tanning and selectively block a stereotyped behavioral program. J Exp Biol 205:2555-2565.

Brezina V (2010) Beyond the wiring diagram: signalling through complex neuromodulator networks. Philos Trans R Soc Lond B Biol Sci 365:2363-2374.

Brocard F, Bardy C, Dubuc R (2005) Modulatory effect of substance P to the brain stem locomotor command in lampreys. J Neurophysiol 93:2127-2141.

Büschges A, Scholz H, El Manira A (2011) New moves in motor control. Curr Biol 21:R513-R524.

Clark AC, del Campo ML, Ewer J (2004) Neuroendocrine control of larval ecdysis behavior in Drosophila: complex regulation by partially redundant neuropeptides. J Neurosci 24:4283-4292.

Cornford A, Kristan WB 3rd, Malnove S, Kristan WB Jr, French KA (2006) Functions of the subesophageal ganglion in the medicinal leech revealed by ablation of neuromeres in embryos. J Exp Biol 209:493-503.

Cottrell CB (1962) General observations on the imaginal ecdysis of blowflies. Trans R Entomol Soc London 114:317-333.

Cottrell CB (1964) Insect ecdysis with particular emphasis on cuticular hardening and darkening. New York: Academic.

Dai L, Dewey EM, Zitnan D, Luo CW, Honegger HW, Adams ME (2008) Identification, developmental expression, and functions of bursicon in the tobacco hawkmoth, Manduca sexta. J Comp Neurol 506:759-774.

Denlinger DL, Zdarek J (1994) Metamorphosis behavior of flies. Annu Rev Entomol 39:243-266.

Dewey EM, McNabb SL, Ewer J, Kuo GR, Takanishi CL, Truman JW, Honegger HW (2004) Identification of the gene encoding bursicon, an insect neuropeptide responsible for cuticle sclerotization and wing spreading. Curr Biol 14:1208-1213.

Dickinson PS (1995) Interactions among neural networks for behavior. Curr Opin Neurobiol 5:792-798.

Dickinson PS (2006) Neuromodulation of central pattern generators in invertebrates and vertebrates. Curr Opin Neurobiol 16:604-614.

Dietzl G, Chen D, Schnorrer F, Su KC, Barinova Y, Fellner M, Gasser B, Kinsey K, Oppel S, Scheiblauer S, Couto A, Marra V, Keleman K, Dickson BJ (2007) A genome-wide transgenic RNAi library for conditional gene inactivation in Drosophila. Nature 448:151-156.

Edwards DH, Heitler WJ, Krasne FB (1999) Fifty years of a command neuron: the neurobiology of escape behavior in the crayfish. Trends Neurosci 22:153-161.

Elliott CJ, Susswein AJ (2002) Comparative neuroethology of feeding control in molluscs. J Exp Biol 205:877-896.

Ewer J, Gammie SC, Truman JW (1997) Control of insect ecdysis by a positive-feedback endocrine system: roles of eclosion hormone and ecdysis triggering hormone. J Exp Biol 200:869-881.

Friesen WO, Kristan WB (2007) Leech locomotion: swimming, crawling, and decisions. Curr Opin Neurobiol 17:704-711.

Gold JI, Shadlen MN (2007) The neural basis of decision making. Annu Rev Neurosci 30:535-574.

Grigliatti T (1998) Transposons-gene tagging and mutagenesis. In: Dro- 
sophila: a practical approach, 2nd edition (Roberts D, ed), pp 85-108. Oxford: Oxford UP.

Halfon MS, Gisselbrecht S, Lu J, Estrada B, Keshishian H, Michelson AM (2002) New fluorescent protein reporters for use with the Drosophila Gal4 expression system and for vital detection of balancer chromosomes. Genesis 34:135-138.

Hedwig B (2006) Pulses, patterns and paths: neurobiology of acoustic behaviour in crickets. J Comp Physiol A Neuroethol Sens Neural Behav Physiol 192:677-689.

Honegger HW, Dewey EM, Ewer J (2008) Bursicon, the tanning hormone of insects: recent advances following the discovery of its molecular identity. J Comp Physiol A Neuroethol Sens Neural Behav Physiol 194:989-1005.

Humphries MD, Gurney K, Prescott TJ (2007) Is there a brainstem substrate for action selection? Philos Trans R Soc Lond B Biol Sci 362:1627-1639.

Kable JW, Glimcher PW (2009) The neurobiology of decision: consensus and controversy. Neuron 63:733-745.

Katz PS, Harris-Warrick RM (1999) The evolution of neuronal circuits underlying species-specific behavior. Curr Opin Neurobiol 9:628-633.

Katz PS, Hooper SL (2007) Invertebrate central pattern generators. In: Invertebrate neurobiology (North G, Greenspan RJ, ed), pp 251-279. Cold Spring Harbor: Cold Spring Harbor Laboratory.

Kien J, Altman JS (1992) Preparation and execution of movement: parallels between insect and mammalian motor systems. Comp Biochem Physiol Comp Physiol 103:15-24.

Kim YJ, Zitnan D, Galizia CG, Cho KH, Adams ME (2006) A command chemical triggers an innate behavior by sequential activation of multiple peptidergic ensembles. Curr Biol 16:1395-1407.

Kingan TG, Gray W, Zitnan D, Adams ME (1997) Regulation of ecdysistriggering hormone release by eclosion hormone. J Exp Biol 200:32453256.

Kow LM, Mobbs CV, Pfaff DW (1994) Roles of second-messenger systems and neuronal activity in the regulation of lordosis by neurotransmitters, neuropeptides, and estrogen: a review. Neurosci Biobehav Rev 18: 251-268.

Kristan WB Jr, Calabrese RL, Friesen WO (2005) Neuronal control of leech behavior. Prog Neurobiol 76:279-327.

Kupfermann I, Weiss KR (1978) The command neuron concept. Behav Brain Sci 1:3-39.

Kupfermann I, Weiss KR (2001) Motor program selection in simple model systems. Curr Opin Neurobiol 11:673-677.

Larimer JL, Moore D (2003) Neural basis of a simple behavior: abdominal positioning in crayfish. Microsc Res Tech 60:346-359.

Leibowitz SF, Wortley KE (2004) Hypothalamic control of energy balance: different peptides, different functions. Peptides 25:473-504.

Luan H, Peabody NC, Vinson CR, White BH (2006a) Refined spatial manipulation of neuronal function by combinatorial restriction of transgene expression. Neuron 52:425-436.

Luan H, Lemon WC, Peabody NC, Pohl JB, Zelensky PK, Wang D, Nitabach MN, Holmes TC, White BH (2006b) Functional dissection of a neuronal network required for cuticle tanning and wing expansion in Drosophila. J Neurosci 26:573-584.

Luo CW, Dewey EM, Sudo S, Ewer J, Hsu SY, Honegger HW, Hsueh AJ (2005) Bursicon, the insect cuticle-hardening hormone, is a heterodi- meric cystine knot protein that activates $\mathrm{G}$ protein-coupled receptor LGR2. Proc Natl Acad Sci U S A 102:2820-2825.

Marder E, Bucher D (2001) Central pattern generators and the control of rhythmic movements. Curr Biol 11:R986-R996.

McNabb SL, Baker JD, Agapite J, Steller H, Riddiford LM, Truman JW (1997) Disruption of a behavioral sequence by targeted death of peptidergic neurons in Drosophila. Neuron 19:813-823.

Mendive FM, Van Loy T, Claeysen S, Poels J, Williamson M, Hauser F, Grimmelikhuijzen CJ, Vassart G, Vanden Broeck J (2005) Drosophila molting neurohormone bursicon is a heterodimer and the natural agonist of the orphan receptor DLGR2. FEBS Lett 579:2171-2176.

Mesce KA, Esch T, Kristan WB Jr (2008) Cellular substrates of action selection: a cluster of higher-order descending neurons shapes body posture and locomotion. J Comp Physiol A Neuroethol Sens Neural Behav Physiol 194:469-481.

Mullins OJ, Hackett JT, Buchanan JT, Friesen WO (2011) Neuronal control of swimming behavior: comparison of vertebrate and invertebrate model systems. Prog Neurobiol 93:244-269.

Nusbaum MP, Blitz DM, Swensen AM, Wood D, Marder E (2001) The roles of co-transmission in neural network modulation. Trends Neurosci 24:146-154.

Paradis S, Sweeney ST, Davis GW (2001) Homeostatic control of presynaptic release is triggered by postsynaptic membrane depolarization. Neuron 30:737-749.

Park JH, Schroeder AJ, Helfrich-Förster C, Jackson FR, Ewer J (2003) Targeted ablation of CCAP neuropeptide-containing neurons of Drosophila causes specific defects in execution and circadian timing of ecdysis behavior. Development 130:2645-2656.

Peabody NC, Diao F, Luan H, Wang H, Dewey EM, Honegger HW, White BH (2008) Bursicon functions within the Drosophila CNS to modulate wing expansion behavior, hormone secretion, and cell death. J Neurosci 28:14379-14391.

Peabody NC, Pohl JB, Diao F, Vreede AP, Sandstrom DJ, Wang H, Zelensky PK, White BH (2009) Characterization of the decision network for wing expansion in Drosophila using targeted expression of the TRPM8 channel. J Neurosci 29:3343-3353.

PfaffDW, Kieffer BL, Swanson LW (2008) Mechanisms for the regulation of state changes in the central nervous system: an introduction. Ann N Y Acad Sci 1129:1-7.

Reynolds SE (1977) Control of cuticle extensibility in wings of adult manduca at time of eclosion: effects of eclosion hormone and bursicon. J Exp Biol 70:27-39.

Ridgel AL, Ritzmann RE (2005) Effects of neck and circumoesophageal connective lesions on posture and locomotion in the cockroach. J Comp Physiol A Neuroethol Sens Neural Behav Physiol 191:559-573.

Swanson LW (2000) Cerebral hemisphere regulation of motivated behavior. Brain Res 886:113-164

Truman JW (1973) Physiology of insect ecdysis. 3. Relationship between hormonal-control of eclosion and of tanning in tobacco hornworm, Manduca-sexta. J Exp Biol 58:821-829.

Truman JW (2005) Hormonal control of insect ecdysis: endocrine cascades for coordinating behavior with physiology. Vitam Horm 73:1-30.

von Philipsborn AC, Liu T, Yu JY, Masser C, Bidaye SS, Dickson BJ (2011) Neuronal control of Drosophila courtship song. Neuron 69:509-522.

Zhou C, Rao Y, Rao Y (2008) A subset of octopaminergic neurons are important for Drosophila aggression. Nat Neurosci 11:1059-1067. 